\title{
Gastro-Resistant Microparticles Containing Sodium Pantoprazole: Stabil- ity Studies and In Vivo Anti-Ulcer Activity
}

\author{
R.P. Raffin ${ }^{1}$, L.M. Colomé ${ }^{1}$, E.E.S. Schapoval ${ }^{1}$, D.S. Jornada ${ }^{1}$, A.R. Pohlmann ${ }^{*}, 2$ and S.S. Guterres ${ }^{1}$ \\ ${ }^{\text {I}}$ Programa de Pós-Graduação em Ciências Farmacêuticas, Universidade Federal do Rio Grande do Sul, Brazil \\ ${ }^{2}$ Departamento de Química Orgânica, Instituto de Química, Universidade Federal do Rio Grande do Sul. Av. Bento \\ Gonçalves 9500, CP 15003, Porto Alegre, RS, Brazil, CEP 91501-970
}

\begin{abstract}
The aim of the present work was to verify the in vivo capacity of pantoprazole-loaded microparticles to protect the gastric mucosa against ulcer formation and to evaluate their stability under accelerated conditions. Pantoprazoleloaded microparticles were prepared by spray-drying in pilot scale, using Eudragit ${ }^{\circledR} \mathrm{S} 100$ as polymer. Transparent glass vials containing drug-loaded microparticles were stored for 6 months at $40^{\circ} \mathrm{C}$ and $75 \% \mathrm{RH}$. Photostability was tested under UVA light. Ulcers were induced by the oral administration of absolute ethanol to rats. Sodium bicarbonate solution, pantoprazole solution and drug-loaded microparticles were tested. Regarding the drug content during the accelerate stability study, samples showed complete encapsulation efficiency and were considered stable. The microencapsulation of pantoprazole reduced its photodegradation. The in vivo evaluation showed that the microparticles presented ulcer index lower than the solutions. Enteric microparticles had acceptable stability under accelerated conditions and were efficient in protecting the stomach against ulceration caused by ethanol.
\end{abstract}

Keywords: Pantoprazole, microparticles, stability, photodegradation, gastro-resistance, anti-ulcer activity.

\section{INTRODUCTION}

Pantoprazole is a proton-pump inhibitor used in the treatment of gastric ulcers, gastro-esophageal reflux disease and Helicobacter pylori infections associated to other drugs, such as metronidazole, clarithromycin or amoxicillin [1,2]. This drug was the first water soluble benzimidazole, 5(difluoromethoxy)-2-[[(3,4-dimethoxy-2-pyridinyl)methyl]sulfinyl]-benzimidazole (Fig. 1), which can be administered intravenously in the form of sesquihydrate sodium pantoprazole.

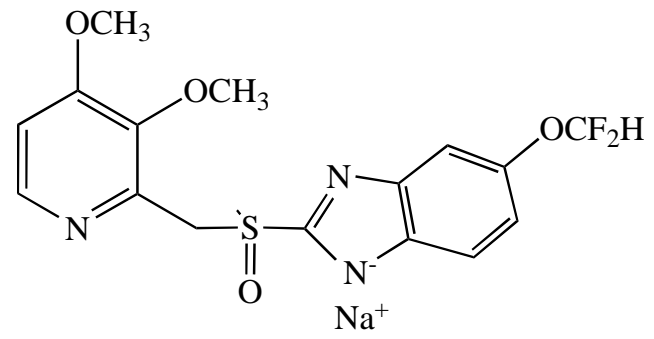

Fig. (1). Chemical structure of sodium pantoprazole.

Pantoprazole is converted to its active form inside the gastric parietal cells, binding irreversibly to the $\mathrm{H}^{+} / \mathrm{K}^{+}$ATPase. Since this conversion must occur inside the parietal-cell canalicular lumen and considering that the prodrug is labile in the stomach environment, the pantoprazole must be absorbed intact by the gastrointestinal tract $[3,4]$. In this way, pantoprazole is intravenously administered after the reconstitution of lyophilized powder or orally administered as gastric-resistant tablets using enteric-coated dosage

\footnotetext{
*Address correspondence to this author at the Departamento de Química Orgânica, Instituto de Química, Universidade Federal do Rio Grande do Sul. Av. Bento Gonçalves 9500, CP 15003, Porto Alegre, RS, Brazil, CEP 91501-970; Tel: +55 51 33086274; Fax: +55 51 33087304;

E-mail: pohlmann@iq.ufrgs.br
}

forms, which prevents pantoprazole from degradation in the gastric juice [5].

In order to administer pantoprazole by the oral route, polymeric microparticles appear to be an interesting device. Despite the more complex and onerous production of the multiple-unit systems, microparticles have several advantages in relation to the single-unit products, including ready and uniform distribution in the gastrointestinal tract, minimizing the risk of local damage caused by a dose dumping effect [6]. Furthermore, microparticles are also less affected by the $\mathrm{pH}$ and the gastric transit time, attain more constant plasma levels, give higher accuracy in reproducibility dose by dose and achieve a slow-release effect [7].

In our previous works, gastro-resistant microparticles were prepared using Eudragit ${ }^{\circledR}$ S100 by two techniques: emulsification/solvent evaporation and spray-drying $[8,9]$. These microparticles were characterized by means of their morphology, packing and flowing properties, water content and dissolution kinetics. The microparticles prepared by emulsification/solvent evaporation had higher particle sizes $(56 \mu \mathrm{m})$ than the microparticles prepared by spray-drying $(7$ - $25 \mu \mathrm{m}$ ). The microparticles prepared by solvent evaporation stabilized $61 \%$ of pantoprazole content after acid exposure. However, when tested in vivo for the anti-ulcer activity, microparticles containing pantoprazole were able to protect the gastric mucosa against the ulceration caused by ethanol. The microparticles were prepared by spray-drying in laboratory scale and the scaling up of the process was investigated. Different parameters and spray-drier designs were tested in pilot scale. The rotating disc atomizer at co-current air/spray contact furnished the microparticles presenting the highest in vitro gastro-resistance $(98 \%)$. These microparticles showed adequate in vitro characteristics, but were not tested in vivo.

The stability of a pharmaceutical product is a key element of quality, and regulatory authorities ensure that useful- 
life claims are realistic and demonstrable. Long-term stability studies are the most reliable demonstration or exploration of a product shelf life [10]. The length of time required for such studies often renders them impractical. Therefore, a reliable alternative to real time stability testing, such as one that can predict rates of decay at temperatures of interest, is clearly required. The method of accelerated storage testing has the ability to predict shelf life at low temperatures and humidity.

Taking all above into account, the aim of this work was to verify the in vivo capacity of pantoprazole-loaded microparticles to protect the gastric mucosa against ulcer formation and to evaluate their stability under accelerated conditions. Additionally, the work was also consecrated to determine the drug release profiles from microparticles after short term stability studies.

\section{MATERIALS AND METHODOLOGY}

Pantoprazole sodium sesquihydrate was obtained from Henrifarma (São Paulo, Brazil). Eudragit ${ }^{\circledR}$ S100 was kindly given by Almapal ${ }^{\circledR}$ (São Paulo, Brazil produced by Rohm ${ }^{\circledR}$, Germany). The polymer average molecular weight is approx. $135,000 \mathrm{Da}$. Acetonitrile was HPLC grade and all other chemicals were analytical grade.

\section{PREPARATION OF PANTOPRAZOLE-LOADED MI- CROPARTICLES}

Pantoprazole-loaded microparticles were prepared in pilot scale as previously described [9]. Briefly, $48 \mathrm{~g}$ of Eudragit $^{\circledR} \mathrm{S} 100$ were dissolved in a NaOH solution $\left(6 \mathrm{~g} . \mathrm{L}^{-1}\right)$. After its complete dissolution, pantoprazole (12 g) was added. The final solution $(1000 \mathrm{~mL})$ was kept at $40^{\circ} \mathrm{C}$ and spray-dried in a pilot spray-dryer (Model PSD 52 APV1Anhydro, Denmark). Temperature and humidity in the room $\left(24{ }^{\circ} \mathrm{C}\right.$ and $54 \%$, respectively) were kept constant. The atomizer used was a rotating disc under the following operating conditions: co-current flow; rotational velocity of atomizer of 30,000 rpm; suspension flow rate of $2{\mathrm{~L} . \mathrm{h}^{-1}}^{-1}$, inlet and outlet air temperatures of $170 \pm 1^{\circ} \mathrm{C}$ and $85 \pm 5^{\circ} \mathrm{C}$, respectively. The process yield was calculated dividing the obtained mass by the sum of the masses of Eudragit ${ }^{\circledR}$ S100, pantoprazole and $\mathrm{NaOH}$, expressed in percentage. Microparticles were prepared in triplicate.

\section{DETERMINATION OF THE DRUG LOADING}

The drug loading was assayed by a validated HPLC method [11] according to ICH [12]. Briefly, an amount of the microparticles, equivalent to the theoretical content of 10 $\mathrm{mg}$ of pantoprazole, was weighed and magnetically stirred with $40 \mathrm{~mL}$ of $0.05 \mathrm{~mol} . \mathrm{L}^{-1} \mathrm{NaOH}$ for $1 \mathrm{~h}$ in a volumetric flask. The volume was completed to $50 \mathrm{~mL}$ and drug concentration was determined after filtration $(0.45 \mu \mathrm{m})$ by HPLC (Perkin Elmer serie 200) using a LiChrospher RP18 (Merck) column. Mobile phase consisted of acetonitrile/phosphate buffer $\mathrm{pH} 7.4(35: 65 \mathrm{v} / \mathrm{v})$, the flow rate was 1 $\mathrm{mL} \cdot \mathrm{min}^{-1}$ and detector wavelength was set at $290 \mathrm{~nm}$.

\section{PARTICLE SIZE AND SCANNING ELECTRON MI- CROSCOPY (SEM) ANALYSES}

SEM analyses were carried out using an accelerating voltage of $20 \mathrm{kV}$ after gold sputtering (Jeol Scanning Microscope JSM - $6060^{\circledR}$ and JSM-5800 ${ }^{\circledR}$, Japan). The microparti- cle size distributions were measured by laser light diffraction (Malvern MasterSizer, model E, UK) after dispersion in isooctane. Average particle size was expressed as the mean volume diameter. Polydispersity was given by a span index, which was calculated by equation 1 .

Span $=\frac{D_{0.9}-D_{0.1}}{D_{0.5}}$

where $\mathrm{D}_{0.9}, \mathrm{D}_{0.5}$, and $\mathrm{D}_{0.1}$ are the particle diameters determined, respectively, at the $90^{\text {th }}, 50^{\text {th }}$, and $10^{\text {th }}$ percentile of the undersized particle distribution curve.

\section{POWDER FLOW CHARACTERIZATION}

Bulk and tapped densities were assessed according to USP 30, as well as the determination of the compressibility index. The angle of repose was assayed as previously described [9]. The angle of repose is the angle between the horizontal and slope of the heap. This angle is a direct indication of the potential flowability of a powder (contact and friction between particles in motion). The angle of repose was measured in a Powder Characteristics Tester, Model PTN (Hosokawa Microns). Flowability was assayed according to the $\mathrm{Ph}$ Eur 5 [13]. Five grams of microparticles were placed inside a funnel and the time to the entire sample to flow was recorded and used as a comparative value among batches.

\section{DIFFERENTIAL SCANNING CALORIMETRY (DSC)}

DSC was performed (DSC-4 Shimadzu, Kyoto, Japan) after sealing the samples (pantoprazole, Eudragit ${ }^{\circledR} \mathrm{S} 100$, their physical mixture and microparticles) in aluminum pans. Calibration was carried out using indium. DSC tracings were performed from $40^{\circ} \mathrm{C}$ to $250{ }^{\circ} \mathrm{C}$ at a rate of $10^{\circ} \mathrm{C} \cdot \mathrm{min}^{-1}$.

\section{DETERMINATION OF WATER CONTENT}

The water content of the samples was determined by Karl Fisher titrimetry (Mettler DL 37 KF Coulometer, Switzerland). Samples were analyzed in duplicate and compared to pure pantoprazole.

\section{IN VIVO ANTI-ULCER ACTIVITY}

Ulcers were induced by the oral administration of absolute ethanol $\left(5 \mathrm{~mL} \cdot \mathrm{kg}^{-1}\right)$ to $24 \mathrm{~h}$ fasted Wistar male rats $(\mathrm{n}=$ 8 ), weighing $200 \mathrm{~g}$. The groups are described in Table $\mathbf{1}$. Formulations (20 mg. $\mathrm{kg}^{-1}$ of drug) were administered orally $1 \mathrm{~h}$ before the administration of ethanol. Prior to the oral administration, rats were anesthetized with ethylic ether. After $2 \mathrm{~h}$ of ethanol administration, animals were sacrificed; the stomachs were removed, opened along the greater curvature and examined for lesion measurements [8].

Ulcer indexes (UI) were calculated using equation 2 .

$U I=\frac{10}{x}$

where $\mathrm{x}$ is the total mucosal area divided by the total ulcerated area.

\section{ACCELERATED STABILITY TESTS}

The stability of drugs and medicines depends on environmental factors as temperature, humidity and light, as well as on the physico-chemical properties of the drug and the 
excipients [14]. The purpose of stability testing is to provide evidence on how the quality of a drug product varies with time and to establish a shelf life for the drug product and recommended storage conditions [10]. Accelerated stability testing are studies designed to increase the rate of chemical degradation or physical change of a drug product by using exaggerated storage conditions as part of the formal stability studies. Transparent glass vials containing $0.5 \mathrm{~g}$ of drugloaded microparticles were stored for 6 months in a stability chamber at $40^{\circ} \mathrm{C}$ and $75 \%$ RH. Sealed and non-sealed vials were evaluated every 30 days for their drug content. The acceptance criteria for the stability tests are 5 percent change in assay from its initial value, or any degradation product's exceeding its acceptance criterion or failure to meet the acceptance criteria for dissolution [10]. Humidity was gravimetrically determined. DSC was performed for the drugloaded microparticles after different times of storage.

Table 1. Groups of Rats (Control 1, Control 2 and Treatment) for the In Vivo Anti-Ulcer Activity

\begin{tabular}{|c|c|}
\hline Groups & Administered Samples \\
\hline \hline Control 1 & Sodium bicarbonate solution (4.2\%) \\
\hline Control 2 & Pantoprazole dissolved in water (2 mg.mL-1) \\
\hline Treatment & $\begin{array}{c}\text { Microparticles dispersed in water } \\
\text { (equivalent to } 2 \mathrm{mg}^{-1} \mathrm{~mL}^{-1} \text { of pantoprazole) }\end{array}$ \\
\hline
\end{tabular}

\section{IN VITRO GASTRO-RESISTANCE EVALUATION}

The gastro-resistance evaluation was performed after 6 months of storage and the results compared to that profile determined just after preparation [9]. In order to ensure the homogeneity of the dispersion and no flotation of the powders, size 0 hard gelatin capsules without coloring agent were used. The capsules were filled with $90 \mathrm{mg}$ of microparticles, corresponding to $16 \mathrm{mg}$ of drug. Dissolution tests were undertaken in USP dissolution apparatus I at $50 \mathrm{rpm}$ and $37^{\circ} \mathrm{C}$. In order to determine if the microparticles were able to release $100 \%$ of the encapsulated drug, the dissolution was evaluated in phosphate buffer $\mathrm{pH} 7.4$ for $120 \mathrm{~min}$. To evaluate gastro-resistance, capsules were prior exposed to $300 \mathrm{~mL}$ of $0.1 \mathrm{~mol} . \mathrm{L}^{-1} \mathrm{HCl}$. After $1 \mathrm{~h}$, an $\mathrm{NaOH}(2.6 \mathrm{~g})$ and $\mathrm{KH}_{2} \mathrm{PO}_{4}(6.12 \mathrm{~g})$ aqueous solution $(600 \mathrm{~mL})$ was added in order to reach the final $\mathrm{pH}$ of 7.4. The samples were collected at predetermined time intervals from 0 up to $180 \mathrm{~min}$. Pantoprazole concentrations were determined by UV spectrophotometry at $295 \mathrm{~nm}$ [8].

The profiles were analyzed by the dissolution efficiency and by model dependent methods using the software Micromath Scientist $2.01[15,16]$. Profiles were tested to fit mono and biexponential equations (equations 3 and 4).

$$
\begin{aligned}
& C=100\left(1-e^{-k t}\right) \\
& C=100\left[1-\left(A e^{-\alpha t}+B e^{-\beta t}\right)\right]
\end{aligned}
$$

In order to have some insight into the drug release mechanism, a very simple and semi-empirical equation to describe drug release from polymeric systems, the power law (Korsmeyer-Peppas model), was also applied (equation 5).

$f t=a t^{n}$
In this equation, $f_{t}$ is the drug dissolved fraction at time $t$, $n$ is the release exponent, indicative of the mechanism of the drug release and $a$ is the constant incorporating structural and geometric characteristics of the drug dosage form [16].

\section{PHOTOSTABILITY DETERMINATION}

Pantoprazole-loaded microparticles and pure pantoprazole were exposed to UVA light for $96 \mathrm{~h}$. The light source was a fluorescent lamp UVA, $130 \mathrm{~V}, 30 \mathrm{~W}$ (Starlux) fixed to a chamber in a horizontal position $22 \mathrm{~cm}$ from the samples. The chamber was internally coated with mirrors in order to distribute light homogeneously. Pure pantoprazole powder and the microparticles powder were put in a very fine layer in watch glasses and placed inside the chamber. Samples were collected at 6,24 and $96 \mathrm{~h}$ and analyzed for the pantoprazole contents by HPLC. Protected samples, completely covered with aluminum foil, were used as dark controls in order to evaluate the influence of a thermally induced drug content the total change.

\section{STATISTICAL ANALYSIS}

One-way analysis of variance was employed for the comparison of the experimental data. The non-parametric test Kruskal-Wallis was used for the in vivo data. Multisample comparison was performed using Student-Neuman-Keuls test.

\section{RESULTS}

\section{Preparation OF Microparticles}

The three batches of pantoprazole-loaded microparticles had yields, particle size averages and drug loading similar to those observed for microparticles previously described [9] (Table 2). The powders yielded 52.7, 54.1, 58.0 g.

Table 2. Characteristics of the Three Batches of Microparticles

\begin{tabular}{|c|c|c|c|}
\hline Batch & Yield (\%) & Encapsulation Efficiency (\%) & Humidity (\%) \\
\hline \hline 1 & 80 & $98.83 \pm 2.07$ & $2.3 \pm 0.4$ \\
\hline 2 & 82 & $97.38 \pm 3.18$ & $2.0 \pm 0.1$ \\
\hline 3 & 88 & $99.55 \pm 3.09$ & $1.7 \pm 0.1$ \\
\hline
\end{tabular}

Drug loading was $179.7 \pm 3.7,177.1 \pm 5.8,181.0 \pm 5.6$ $\mathrm{mg} / \mathrm{g}$ and all powders showed low humidity, demonstrating that the spray-drying process was efficient. The particle mean size was $23.0 \pm 0.6 \mu \mathrm{m}$ and the span values showed low and narrow particle size distribution (Table 3). SEM analyses demonstrated that the microparticles presented spherical shape and blowholes (Fig. 2).

Table 3. Particle Size Distribution of the Three Batches of Microparticles

\begin{tabular}{|c|c|c|c|c|}
\hline Batch & Mean Size $(\mu \mathbf{m})$ & $\mathbf{D}_{\mathbf{0 . 1}}(\mu \mathbf{m})$ & $\mathbf{D}_{\mathbf{0 . 9}}(\mu \mathbf{m})$ & Span \\
\hline \hline 1 & 23.7 & 5.1 & 39.6 & 1.4 \\
\hline 2 & 22.7 & 4.9 & 38.5 & 1.4 \\
\hline 3 & 22.6 & 4.7 & 41.3 & 1.6 \\
\hline
\end{tabular}




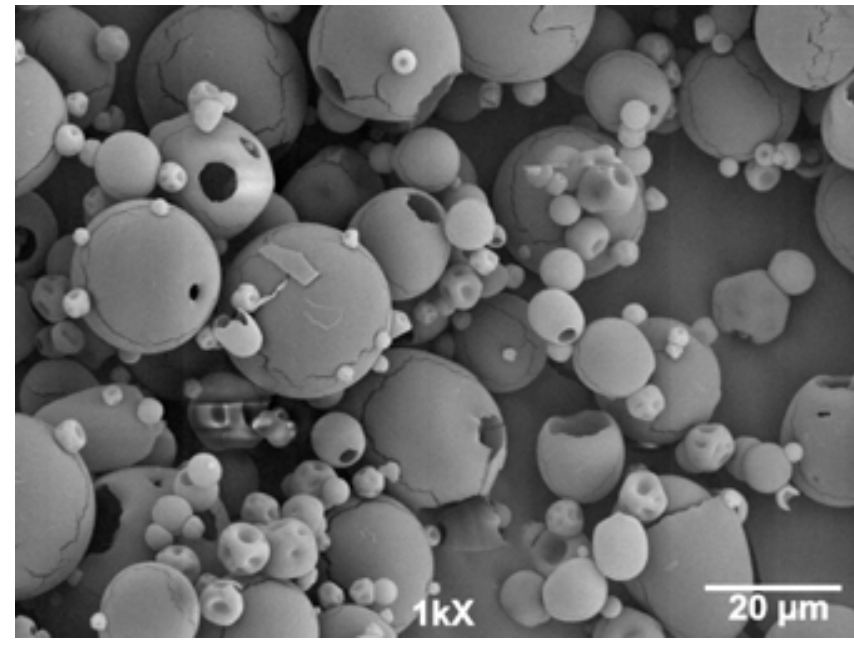

Fig. (2). Photomicrograph (photo width $=125 \mu \mathrm{m}$ ) of the microparticles just after preparation.

\section{POWDER FLOW CHARACTERIZATION}

The three batches of pantoprazole-loaded microparticles presented bulk densities of 0.27, 0.20, and $0.19 \mathrm{~g} . \mathrm{cm}^{-3}$. Tapped densities were $0.42,0.34$ and $0.34 \mathrm{~g} . \mathrm{cm}^{-3}$. All powders presented high compressibility indexes, mainly due to the reduced particle size (Table 4). The angle of repose was $43.5 \pm 3.2^{\circ}$ corroborating with compressibility results. In the flowability test, all samples failed to flow.

Table 4. Powder Flow Properties of the Microparticles

\begin{tabular}{|c|c|c|}
\hline Batch & Carr Index & Angle of Repose $\left(^{\circ}\right)$ \\
\hline \hline 1 & $35.6 \pm 0.8$ & $40.8 \pm 1.1$ \\
\hline 2 & $40.5 \pm 1.2$ & $42.7 \pm 3.8$ \\
\hline 3 & $40.0 \pm 1.1$ & $47.1 \pm 1.4$ \\
\hline
\end{tabular}

\section{DIFFERENTIAL SCANNING CALORIMETRY}

DSC analyses (Fig. 3) showed an endothermic peak at $130^{\circ} \mathrm{C}$, followed by degradation of pantoprazole at $190^{\circ} \mathrm{C}$ (exothermic). Melting and dehydratation of pantoprazole are parallel processes [17]. Eudragit ${ }^{\circledR}$ S100 (pure sample) presented an endothermic peak at $69^{\circ} \mathrm{C}$, as previously observed [18]. Regarding the physical mixtures of the drug and the commercial polymer, the curve showed two endothermic peaks, one correlated to the polymer $\left(64^{\circ} \mathrm{C}\right)$ and the other one to pantoprazole $\left(130{ }^{\circ} \mathrm{C}\right)$. In addition, an exothermic peak correlated to the pantoprazole degradation $\left(190^{\circ} \mathrm{C}\right)$ was also observed. For microparticles, one peak at $75^{\circ} \mathrm{C}$ was observed suggesting that the drug is molecularly interacting with the polymer, as well as the microparticles stabilized the drug restraining its degradation.

\section{ACCELERATED STABILITY TEST}

Within 180 days of the stability tests, vials were weighed monthly. The increase of the weight was $0.4 \%$ for the sealed vials. Non-sealed vials had variation of weight within 5 months similar to sealed vials. In the sixth month, the weight increased 3\%. These results indicated that pantoprazole microparticles are not hygroscopic, but should be stored protected from humidity.

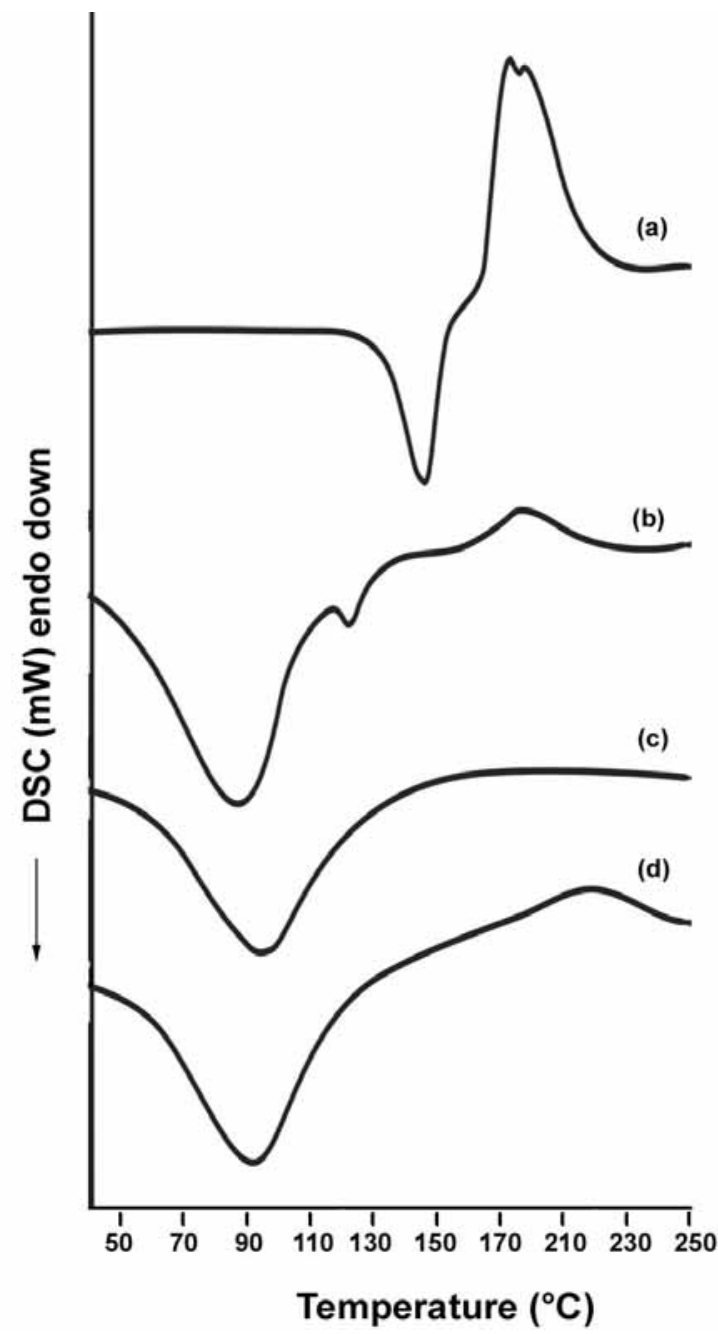

Fig. (3). DSC tracings of (a) PAN, (b) physical mixture (polymer to drug 4:1 w/w ratio), (c) Eudragit ${ }^{\circledR}$ S100 and (d) microparticles.

Regarding the drug content during the accelerated stability study, both samples, from sealed and non-sealed vials presented similar results. As shown in Fig. (4), samples were stable during the test.

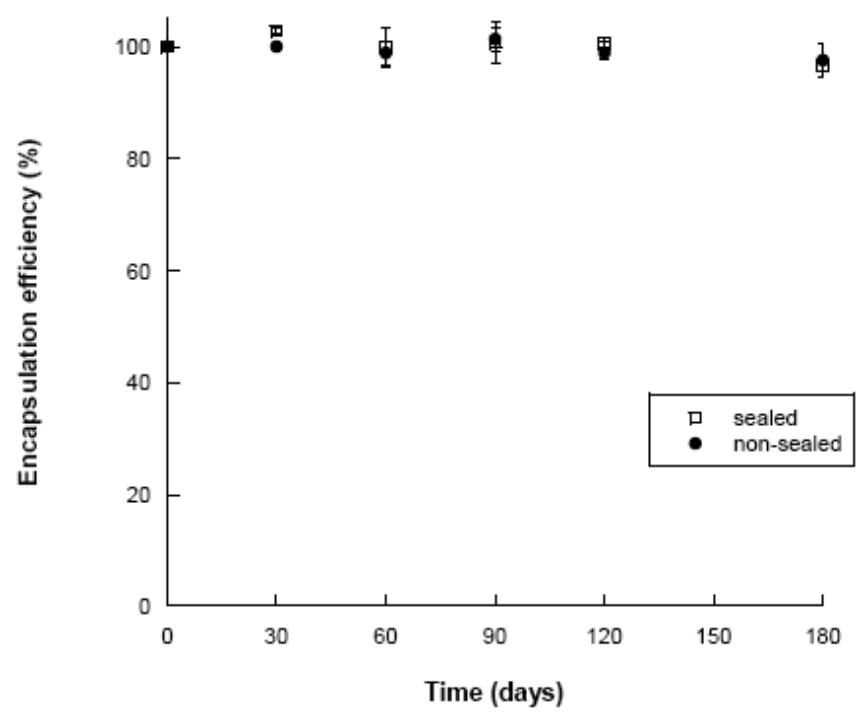

Fig. (4). Microparticles encapsulation efficiency during the accelerated stability tests for the sealed and non-sealed vials. 
After 180 days of storage in the stability chamber, particles showed shape and characteristics very similar to those of the microparticles recently prepared (Fig. 2). The microparticles seem more agglomerated after storage.

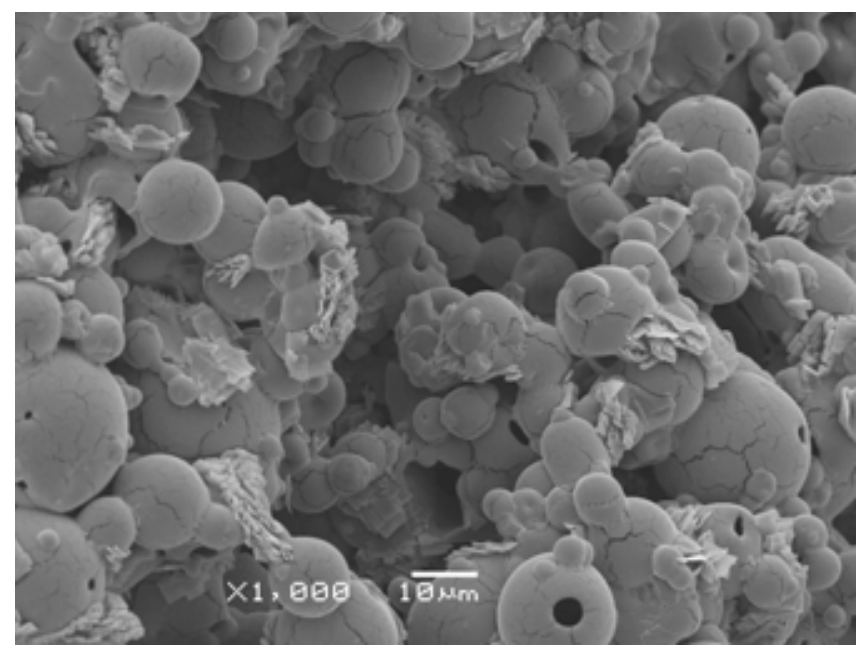

Fig. (5). Photomicrograph (photo width $=125 \mu \mathrm{m}$ ) of the microparticles after 180 days of the accelerated stability studies.

Concerning the DSC analyses during the storage period, the thermogram after 30 days did not show differences compared to that of the microparticles recently prepared. Regarding the subsequent months, an increase of specific heat was verified at $195^{\circ} \mathrm{C}$, corresponding to the pantoprazole degradation. After 6 months, the specific heat increased from 0.16 to $0.75 \mathrm{cal} . \mathrm{g}^{-1}$. No difference was verified for the peak corresponding to the polymer. No additional peaks were observed (Fig. 6).

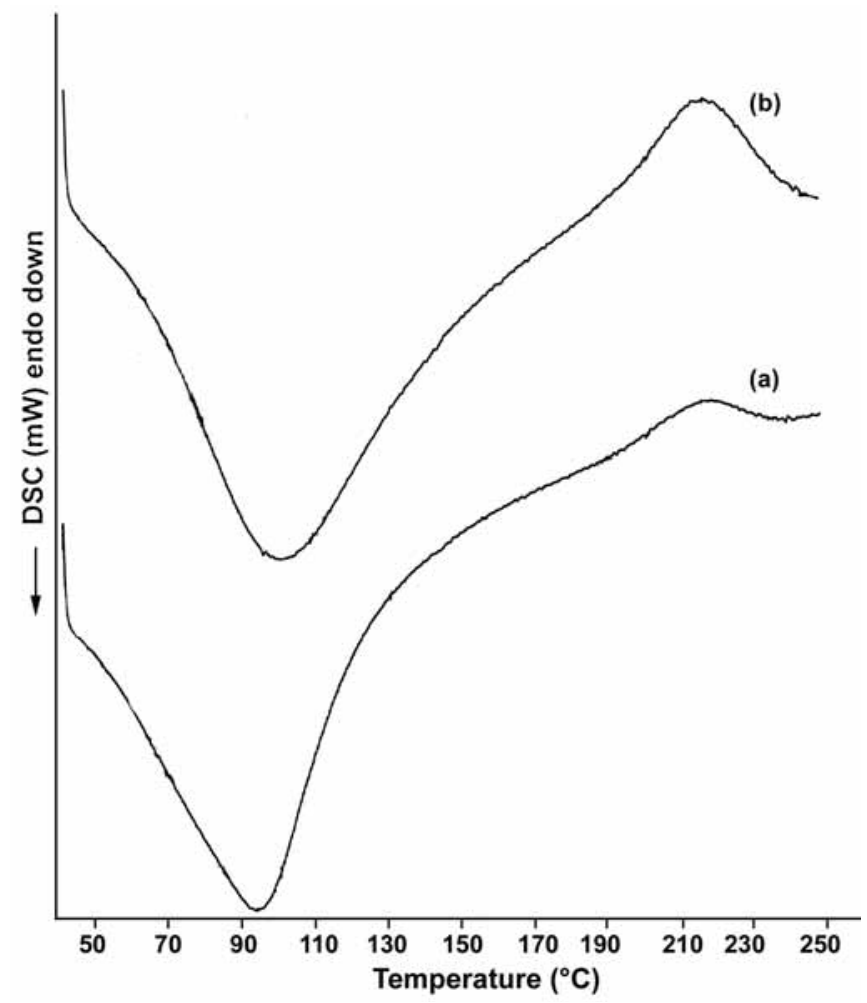

Fig. (6). DSC tracings of the microparticles during the accelerated stability studies at (a) 30 days and (b) 180 days.

\section{GASTRO-RESISTANCE EVALUATION}

Regarding the gastro-resistance evaluation before and after the stability test, it was verified a difference of $8.8 \pm$ $2.3 \%$ in the total amount of drug released. Just after preparation, microparticles were able to stabilize $98 \pm 2.1 \%$ of the drug content. After 180 days of storage, $90 \pm 5.3 \%$ of the drug was stable after the acid step. Although the microparticles showed a reduction of drug content, the value is still in the acceptance criteria of the pharmacopoeias [19,20] (Fig. 7). The encapsulation efficiencies were $82.4 \pm 2.5 \%$ and 76.0 $\pm 4.4 \%$ for times 0 and 180 days, respectively. The encapsulation efficiencies did not present significant difference $(\mathrm{p}=$ 0.169 ) within the period of the stability experiment.

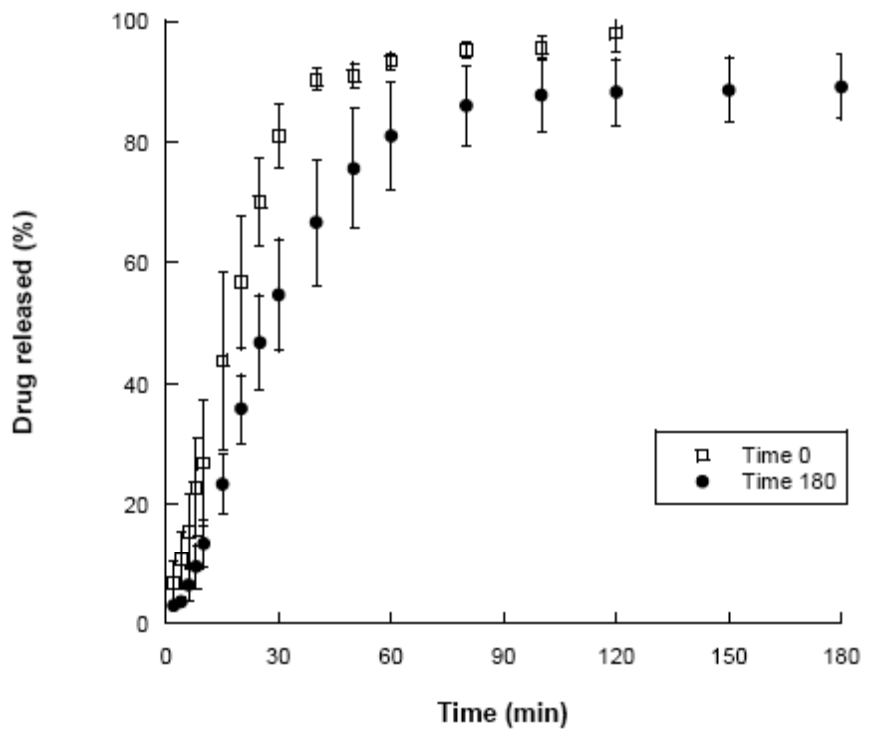

Fig. (7). Drug release from microparticles before and after the accelerated stability tests for sealed vials in phosphate buffer at $\mathrm{pH}$ 7.4 after $1 \mathrm{~h}$ in $0.1 \mathrm{M} \mathrm{HCl}$.

The profiles were modeled using the monoexponential equation. The half-life was calculated based on the kinetic constant $(\mathrm{k})$. Drug release from the microparticles at $\mathrm{t}=0$ min presented $t_{1 / 2}$ of $16.1 \pm 3.7 \mathrm{~min}$ and at $\mathrm{t}=180 \mathrm{~min}, \mathrm{t}_{1 / 2}$ of $28.9 \pm 6.4 \mathrm{~min}$.

The modeling of the microparticle profiles using the Korsmeyer-Peppas model (Fig. 8) showed $n$ value of $1.02 \pm$ 0.02 for the sample recently prepared and $n$ of $1.27 \pm 0.10$, for the microparticles after 180 days of storage.

\section{PHOTOSTABILITY}

Photostability was evaluated for $96 \mathrm{~h}$ (Table 5). After $6 \mathrm{~h}$ of light exposure no difference in the drug content was observed between pure pantoprazole or drug-loaded microparticles (98.7 and 99.2\%, respectively). After 24 h, dark controls showed that pure pantoprazole was affected by temperature (drug content of $45 \%$ ), but the microparticles were not (drug content of 92\%). When exposed to light, pure pantoprazole was degraded almost $70 \%$. However, drug-loaded microparticles exposed to light presented a degradation of $23 \%$. The dark controls after $96 \mathrm{~h}$ of experiment showed decay in pure pantoprazole concentration of $60 \%$ and in the drug-loaded microparticles of 20\%. Exposing pure pantoprazole and the pantoprazole-loaded microparticles to $96 \mathrm{~h}$ of 


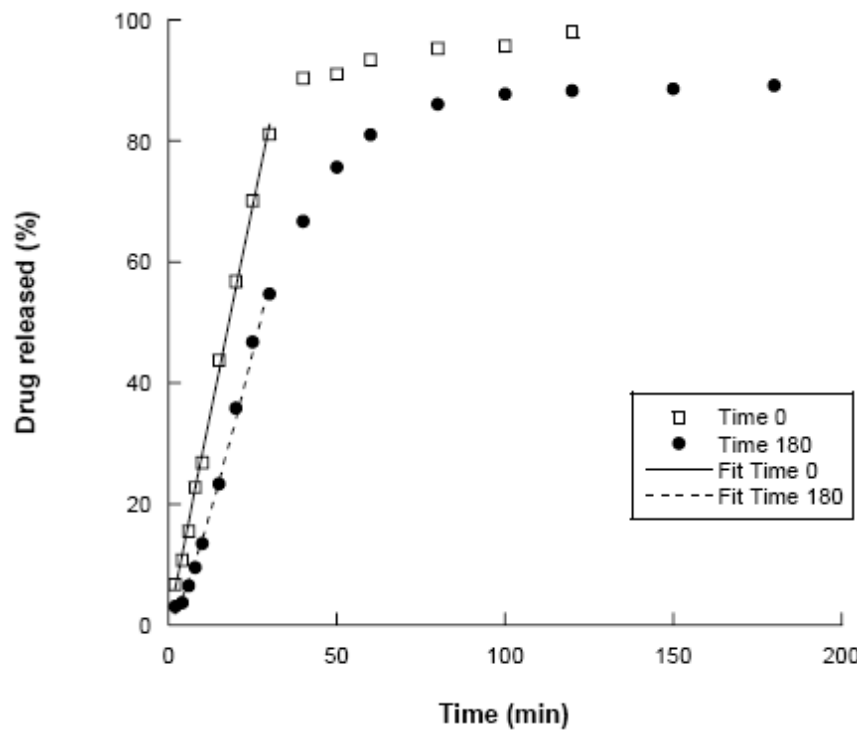

Fig. (8). Mathematical modeling of drug release profiles to the Korsmeyer-Peppas equation.

UVA light, pure pantoprazole was unstable and the sample presented only $11.6 \%$ of non-degraded pantoprazole (Table 5). On the other hand, when exposed to light, the drugloaded microparticles were able to protect $54.4 \%$ of the initial pantoprazole content.

Table 5. Pantoprazole Concentration After Exposure to UVA Light (130 V, 30 W)

\begin{tabular}{|c|c|c|c|}
\hline \multirow{2}{*}{ Sample } & \multicolumn{3}{|c|}{$\begin{array}{c}\text { Pantoprazole Concentration (\%) After the Exposure } \\
\text { Period }\end{array}$} \\
\cline { 2 - 4 } & $\mathbf{6 ~ h}$ & $\mathbf{2 4} \mathbf{~ h}$ & $\mathbf{9 6 ~ h}$ \\
\hline \hline Pantoprazole & $98.7 \pm 1.0$ & $32.6 \pm 0.2$ & $11.6 \pm 2.9$ \\
\hline Microparticles & $99.2 \pm 0.8$ & $78.4 \pm 1.6$ & $54.4 \pm 1.9$ \\
\hline
\end{tabular}

\section{IN VIVO ANTI-ULCER ACTIVITY}

Oral administration of ethanol to the control groups clearly showed hemorrhagic lesions developed in the glandular portion of the stomach (Fig. 9).

The in vivo evaluation showed that ulcer index values were $0.58 \pm 0.13$ for the sodium bicarbonate solution, $0.46 \pm$ 0.17 for the sodium pantoprazole solution and $0.13 \pm 0.05$ for the pantoprazole-loaded microparticles (Fig. 10). The Kruskal-Wallis test detected statistical differences ( $\mathrm{p}=$ 0.002 ) between the ulcer indexes. The multiple analyses (Student-Newman-Keuls) showed that the pantoprazoleloaded microparticles presented a gastric ulcer index statistically lower than the sodium bicarbonate solution $(\mathrm{p}=0.001)$ and the sodium pantoprazole solution $(\mathrm{p}=0.021)$. The percentages of ulceration inhibition were 21 and $78 \%$ after the administration of pantoprazole aqueous solution and microparticles, respectively.

\section{DISCUSSION AND CONCLUSIONS}

The selection of the microencapsulation technique depends largely on the physicochemical properties of the drug. For the entrapment of pantoprazole, an oil-in-oil emulsion followed by solvent evaporation was reported [8]. Pantoprazole was also microencapsulated by spray-drying using $\mathrm{Eu}-$ dragit $^{\circledR}$ S100 $[9,21]$. These microparticles presented advantages such as high values for gastro-resistance and prompt dissolution of the drug. Three replicates were produced on three different days demonstrating the reproducibility of the technique [21]. In the present work, the spray-drying operational conditions were established based on the optimal conditions previously determined [9]. The three batches of microparticles presented acceptable and similar yields. Comparing the results with previous data [22] also produced at laboratory scale, the yields increased from $50 \%$ to $80 \%$. Encapsulation efficiency was complete and very homogeneous, indicating that no loss of active compound occurred during spray-drying (Table 2). Humidity was less than $2 \%$, denoting the effectiveness of the drying process. The results of mean particle size and size distributions of microparticles recorded by laser light diffraction technique on a population basis were found to be unimodal with a narrow size distribution (Table 3). Briefly, the microparticles presented moisture content, particle size and polydispersity adequate and similar among the three batches evaluated. In this way, the process was considered reproducible.

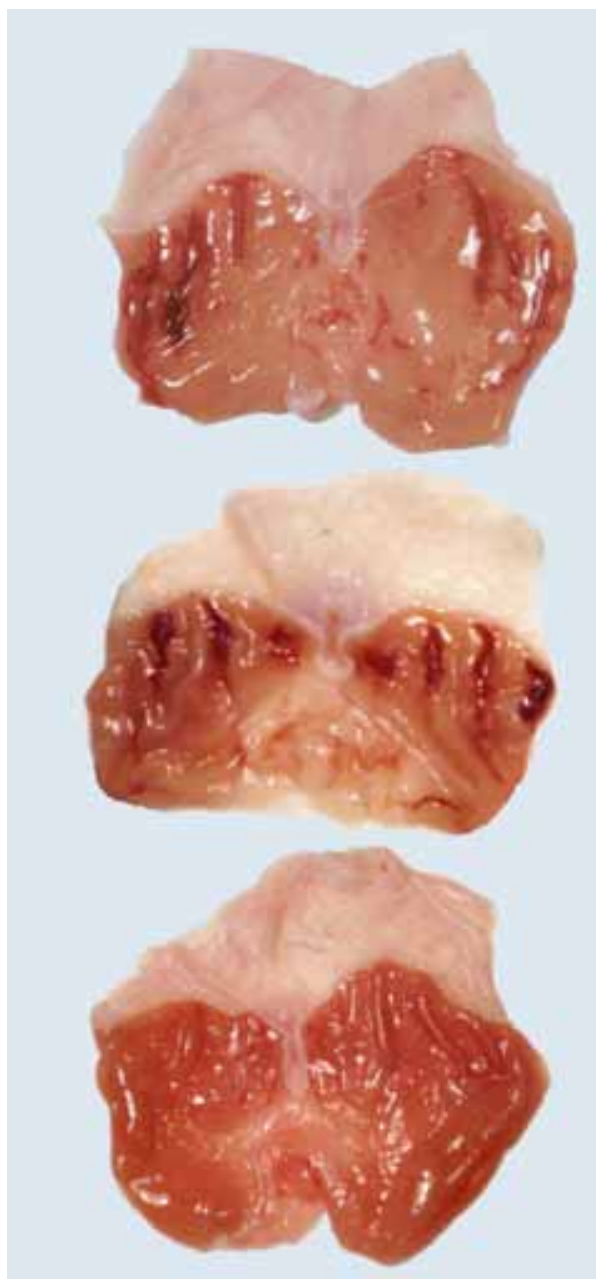

Fig. (9). Photographs of the stomachs opened along the greater curvature. From top to bottom: stomachs after administration of bicarbonate solution, pantoprazole aqueous solution (showing the hemorrhagic lesions developed in the glandular portion of the stomach) and microparticle aqueous dispersion (no lesions observed). 


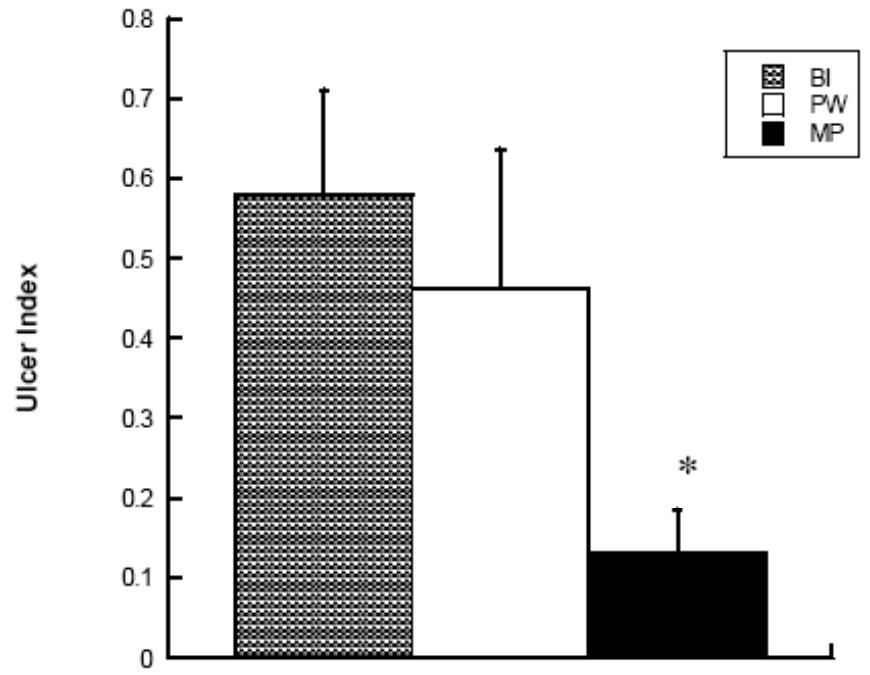

Fig. (10). Ulcer indexes for the bicarbonate solution (BI), pantoprazole aqueous solution (PW) and microparticles dispersed in water (MP). The MP group was statistical different $(\alpha=0.05)$ from the other two*.

Particles were spherical and hollow (Fig. 2). Because of the high concentration of solids in the liquid feed, solids will come out of solution at the surface of the droplet first, leading to the formation of a crust around a hollow particle. In this case, the spray-drying process resulted in puffing or ballooning and cracking of the particles $[9,23]$. It is also observed that pilot-scale powders presented large holes due to the rapid evaporation of water [24]. We can classify the microparticles as hollow microspheres.

The microparticle powders presented very poor flow (Table 4). The compressibility index, angle of repose and flowability corroborated with the low density values. These results suggest that the spray-dried microparticles are likely to have poor flowability, a constraint to be considered in further tableting experiments. This characteristic occurs as a consequence of small particle size and high interparticulate cohesiveness [25].

Concerning the DSC analyzes of the microparticles, the drug peak disappeared compared to the physical mixture (Fig. 3). As previously reported in microparticle formulations the disappearance of melting peaks of drugs indicates their encapsulation [26]. The results suggest that pantoprazole-loaded microparticles are composed by a homogeneous phase, in which the drug is dissolved in the polymer. The major problem of solid dispersions is the result of long-term stability issues such as the appearance of crystalline drug and the resulting decrease in dissolution rate [27, 28]. Fig. (6) shows no endothermic peak of pantoprazole, indicating that no relevant phase separation took place during storage. The result suggests that the material agglomerated with the microparticles in Fig. (5) is not drug crystals.

The in vivo anti-ulcer evaluation demonstrated that microparticles were able to reduce ulcer formation caused by oral administration of ethanol (Fig. 9). Ethanol-induced gastric lesions are due to stasis in gastric mucosa, which contributes to the development of the hemorrhage and necrotic aspects of the tissue injury [29]. The gastric lesions caused by ethanol have been attributed to free radical formation and subsequent formation of lipid peroxidation products [29].
The induction of ulcers by ethanol was considered a good model to evaluate the effect of pantoprazole once it has been already described that there is a lack of interaction between pantoprazole and ethanol in terms of their pharmacokinetics [30]. Ethanol-induced ulcer formation is not inhibited by cimetidine, but it is inhibited by pantoprazole and its analogous.

A shelf live of 24 months can be attributed to products that presented less than $5 \%$ of reduction of the drug during the accelerate stability tests and did not present any degradation product over limits [14]. Considering this statement and our results, the pantoprazole-loaded microparticles could have a 24 month period of shelf life, but this must be confirmed by long-term stability studies. Solid interactions between omeprazole and enteric polymers were investigated at accelerated conditions for month [31]. After 1 month of storage, omeprazole mixed to Eudragit ${ }^{\circledR}$ L100 presented less than $1 \%$ of omeprazole degradation. Eudragit ${ }^{\circledR}$ L100 and S100 are anionic copolymers formed by methacrylic acid and methyl methacrylate (ratio 1:1 and 1:2, respectively). As it was expected also for pantoprazole, the solid interaction between drug and polymer had no influence on pantoprazole stability. Indeed, acrylic polymers have shown good moisture-protective properties and the water was not available for chemical interactions between drug and polymer [31].

The release rate in monoexponential curves is dependent on the initial concentration. Considering that after 180 days, a reduction of the drug content was verified, a slower release from these microparticles was expected. The reduction of the gastro-resistance value can be explained by the presence of cracking in some microparticles after storage and consequent exposure of pantoprazole to the acid medium.

Concerning the mathematical modeling fitting the Korsmeyer-Peppas model for spherical particles, the exponent $n$ of 0.43 indicates that the release mechanism is governed by Fickian diffusion and $n$ higher than 0.85 it is governed by swelling of polymer (Case-II transport or super Case-II transport) [32]. The values of $n$ between 0.43 and 0.85 for spherical particles indicates that the mechanism is governed by both phenomena (anomalous transport) [32]. The $n$ values are obtained from the initial portion of the curve (between $60 \%$ and $80 \%$ of drug release) according to the literature $[33,34]$. The exponent $n$ shows that pantoprazole release mechanism is based on super Case-II transport (non-Fickian mechanism). The mechanism of drug release did not change after 180 days of storage. The release mechanism was found to be the same that melatonin-loaded nanocapsules-coated microparticles prepared with Eudragit ${ }^{\circledR}$ S100 [16]. In both cases, drug release can be explained by the superposition of swelling, relaxation and dissolution of the polymer, which dissolves in $\mathrm{pH}$ values above 7.0 [35].

Regarding the photostability evaluation, pantoprazole showed great instability when exposed to UVA light. However, microparticles were able to protect the drug from light exposure. These results demonstrated that polymeric microparticles increased pantoprazole photostability, facilitating its manufacturing allowing light exposition. Lipospheres have been described to enhance photostability of molecules as melatonin [36]. However, there are no previous reports on the reduction of the photodegradation of drugs by polymeric microencapsulation as far as we know. In this way, panto- 
prazole-loaded microparticles were effective not only in stabilizing the drug in acid medium as increasing the in vivo effect and, finally, reducing the photodegradation. It should be noted that these studies were conducted at accelerated conditions intended to promote the degradation of both the pure pantoprazole and the drug-loaded microparticles. Studies under conditions representing the conventional storage (e.g., $25^{\circ} \mathrm{C}$, ambient humidity) are needed to fully assess the effects of these parameters. Nevertheless, the results presented here demonstrate the potential of pantoprazolemicroparticles to improve photostability of pure drug.

In conclusion, the spray-drying process to produce pantoprazole-loaded microparticles was reproducible and the microparticles showed adequate physico-chemical characteristics for drug delivery. Microparticles were formed by a homogeneous phase consisting of Eudragit ${ }^{\circledR}$ S100 and pantoprazole. The estimated shelf life for the microparticles was 24 months. The microparticles were able to stabilize pantoprazole, protecting the drug from acid exposure and light. The in vivo evaluation corroborated with the in vitro results showing that pantoprazole-loaded microparticles were efficient in protecting the stomach against ulcer formation.

\section{ETHICAL APPROVAL OF STUDIES}

The protocol of the in vivo experiments was approved by the Ethical Committee (deliberation number 2003247, Universidade Federal do Rio Grande do Sul, Brazil).

\section{ACKNOWLEDGEMENTS}

Authors thank CNPq/MCT and Fapergs for the financial support. R. P. Raffin and L. M. Colomé thank Capes for their fellowships.

\section{REFERENCES}

[1] Fitton A, Wiseman L. Pantoprazole - a review of its pharmacological properties and therapeutic use in acid-related disorders. Drugs 1996; 51: 460-82.

[2] Poole P. Pantoprazole. Am J Health Syst Pharm 2001; 58: 9991008.

[3] Cheer S, Prakash A, Faulds D, Lamb H. Pantoprazole- An Update of its pharmacological properties and therapeutic use in the management of acid-related disorders. Drugs 2003; 63: 101-32.

[4] Sachs G, Shin JM, Prathaand V, Hogan D. Synthesis or rupture: duration of acid inhibition by proton pump inhibitors. Drugs Today 2003; 39: 11-4.

[5] Avner D. Clinical Experience with pantoprazole in gastro esophageal reflux disease. Clin Ther 2000; 22: 1170-85.

[6] Lin SY, Kao YH. Tablet study of spray-dried sodium diclofenac enteric-coated microcapsules. Pharm Res 1991; 8: 919-24.

[7] Fu YJ, Mi FL, Wong TB, Shyu SS. Characteristic and controlled release of anticancer drug loaded poly(D,L-lactide) microparticles prepared by spray drying technique. J Microencapsul 2001; 18: 733-47.

[8] Raffin RP, Colomé LM, Guterres SS, Pohlmann AR. Preparation, characterization and in vivo anti-ulcer evaluation of pantoprazoleloaded microparticles. Eur J Pharm Biopharm 2006; 63: 198 - 204.

[9] Raffin RP, Guterres SS, Pohlmann AR, Ré MI. Powder characteristics of pantoprazole delivery systems produced in different spraydryer scales. Drying Tech 2006; 24: 339-48.

[10] International Conference on Harmonisation of Technical Requirements for Registration of Pharmaceuticals for Human Use. Stability Testing of New Drug Substances and Products (Q 1A (R2)) 2003.

[11] Raffin RP, Colomé LM, Guterres SS, Pohlmann AR. Validation of analytical methodology by HPLC for quantification and stability evaluation of sodium pantoprazole. Quim Nova 2007; 30: 1001-5.
[12] International Conference On Harmonisation Of Technical Requirements For Registration Of Pharmaceuticals For Human Use (ICH), "Validation of analytical procedures: methodology", 1996.

[13] European Pharmacopoeia. $5^{\text {th }}$ ed., Strasbourg, France, Council of Europe 2005.

[14] Brazilian National Health Surveillance Agency. Stability testing guideline RE 1, July 29, 2005.

[15] Beck RCR, Pohlmann AR, Benvenutti EV, Dalla Costa T, Guterres SS. Nanostructure-coated Diclofenac-loaded Microparticles: Preparation, Morphological Characterization, in vitro Release and in vivo Gastrointestinal Tolerance. J Braz Chem Soc 2005; 16: 1233-40.

[16] Schaffazick SR, Pohlmann AR, Mezzalira G, Guterres SS. Development of Nanocapsule Suspensions and Nanocapsule Spray-Dried Powders Containing Melatonin. J Braz Chem Soc 2006; 17: 562-9.

[17] Zupancic V, Ograjsek N, Kotar-Jordan B, Vrecer F. Physical characterization of pantoprazole sodium hydrates. Int J Pharm 2005; 291: 59-68.

[18] Cilurzo F, Minghetti P, Selmin F, Casiraghi, A, Montanari L. Polymethacrylate salts as new low-swellable mucoadhesive materials. J Control Rel 2003; 88: 43-53.

[19] United States Pharmacopeia. Rockville, United States, United States Pharmacopeial Convention, 2007.

[20] Farmacopeia Brasileira. São Paulo, Brazil. Ed. Atheneu 1988.

[21] Raffin RP, Jornada DS, Ré MI, Pohlmann AR, Guterres SS. Sodium Pantoprazole-loaded enteric microparticles prepared by spray drying: effect of the scale of production and process validation. Int J Pharm 2006; 324: 10-8.

[22] Colomé LM, Raffin RP, Jornada DS, Pohlmann AR, Guterres SS Pantoprazole-loaded Eudragit blended microparticles: preparation, characterization, in vitro gastro-resistance and in vivo anti-ulcer evaluation. J Drug Del Sci Tech 2007; 17: 113-8.

[23] Goula, A, Adamopoulos K, Kazakis, NA. Influence of Spray Drying Conditions on Tomato Powder Properties. Drying Tech 2004; 22:1129-51.

[24] Goula, A, Adamopoulos K. Spray drying of tomato pulp: Effect of feed concentration. Drying Tech 2004; 22: 2309-30.

[25] Billon A, Bataille B, Cassanas G, Jacob M. Development of spraydried acetaminophen microparticles using experimental designs. Int J Pharm 2000; 203: 159-68.

[26] Ford JL, Timmins P. Drug delivery systems. In: Pharmaceutical Thermal Analysis-Techniques and Applications. New York, Ellis Horwood Limited. 1999; 190-200.

[27] Zahedia P, Lee PI. Solid molecular dispersions of poorly watersoluble drugs in poly(2-hydroxyethyl methacrylate) hydrogels. Eur J Pharm Biopharm 2007; 65: 320-8.

[28] Lovrecich M, Nobile F, Rubessa F, Zingone G. Effect of ageing on the release of indomethacin from solid dispersions with Eudragits. Int J Pharm 1996; 131: 247-55.

[29] Shah PJ, Gandhi MS, Shah MB, Goswami SS, Santani D. Study of Mimusops elengi bark in experimental gastric ulcers. J Ethnopharmacol 2003; 89: 305-11.

[30] Heinze H, Fischer R, Pfützer R, Teyssen S, Singer MV. Lack of Interaction between Pantoprazole and Ethanol A Randomised, Double-Blind, Placebo-Controlled Study in Healthy Volunteers. Clin Drug Invest 2001; 21: 345-51.

[31] Stroyer A, McGinity JW, Leopold CS. Solid State Interaction between the Proton Pump Inhibirot Omeprazole and Various Enteric Coating Polymers. J Pharm Sci 2006; 95: 1342-53.

[32] Siepmann J, Peppas NA. Modeling of drug release from delivery systems based on hydroxypropylmethylcellulose (HPMC). Adv Drug Del Rev 2001; 48:139-57.

[33] Costa P, Lobo JMS. Modeling and comparison of dissolution profiles. Eur J Pharm Sci 2001; 13: 123-33.

[34] Korsmeyer RW, Gurny R, Doelker E, Buri P, Peppas NA. Mechanism of solute release from porous hydrophilic polymers. Int $\mathbf{J}$ Pharm 1983; 15:25-35.

[35] Beten BD, Gelbcke M, Diallo B, Moës AJ. Interaction between dipyridamole and Eudragit S. Int J Pharm 1992; 88: 31-7.

[36] Tursilli R, Casolari A, Iannuccelli V, Scalia S. Enhancement of melatonin photostability by encapsulation in lipospheres. J Pharm Biomed Anal 2006; 40: 910-4. 